\title{
Role of Nurses Today in Nepal
}

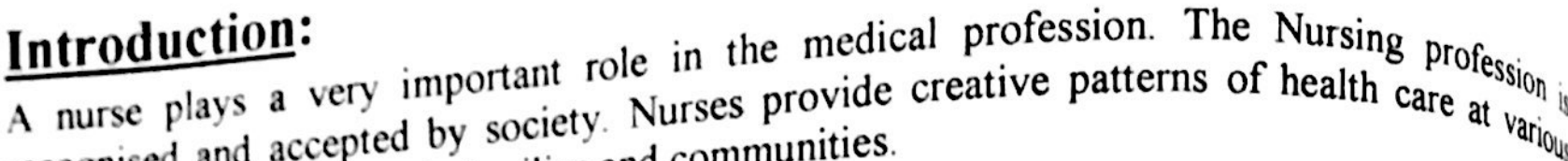

T/Capt. Anita Adhikari
Master Degree in Nursing
Birendra Hospital, Chhauni levels, assisting individuals families and communities

A qualified nurse is one who has completed the basic nursing education programme. The person being authorised to provide nursing wink logically, critically and make sound judgments. Thes and care of the sick and dying. Nurses knowledge to assist mankind. They develop self-reliance ise their acquired technical skils and preventing disease. They also help to maintain and restore people, promoting

We, nurses are concerned with change in self, group and social system and play the nursing role according to the changing need of the society. At present the 9th. National Health Care plan has been focused on the health care delivery system in adopting a comprehensive health care year 2000 A D" It is based on the country's resources, Therefore, T U IO M has adopted primary health care system and introduce it into curriculum of 1987

Elemem of PH. C. Inclindes (Primary Health Care):

- Heath education

- Supply of adequate food and nutrition

- Supply of proper water and good sanitation

- Service for maternal child health and family planning (Reproductive Health)

- Immunization for all the children and pregnant women

- Control of communicable disease

- Treatment of minor illness and supply of essential drugs

Basic Principle of P.H.C

- Inersectoral action

- Appropriate technology

- Community involvement

- Equitable distribution

Levels of P.H.C

Service to all

- Individual, Family and community are the primary levels.

- Health facilities for referral system for the achievement of secondary and tertiary levels of health care from peripheral to central levels.

Before this slogan, the health care delivery system was hospital oriented and people has to go seek health care at the hospital. After P.H.C was established in health care has been community oriented Its main objectives are prevention of disease, promotion of health and curative health service. The National Health Policy has been converted according to the International and National demands. Job descriptions of the health worker has been developed to reflect their own professional rules. Nurses in Nepal have to works in a way that fulfill the National health needs. 
people in Nepal are suffering from many diseases and illness. The factors causing ill health in our country are as follows:

- Ignorance

- Illiteracy

- Superstition

- Poor nutrition

- Poor environment sanitation

- Lack of good water supply

- Poor hygienic habit

- Negligence of treatment of minor illness

- Large family size

- Deforestation

- Alcoholism

- High population growth (2.1\%).

- Establishment of refugee camps

- Drug abuse

- Spread of communicable diseases

- Street kids

- Believe on supernatural forces

The present estimated population of Nepal is 2,11,26,636 millions, the birth rate per 1000 is -39.5 , death rate is-11.9 per 1000, I.M.R. -79 per 1000 live birth, M.M.R -515 per 100,000, growth rate $2.1 \%$ and T.F.R - 5.7 per women.

Nurses are prepared according to the National Health need. This binding is maintained by Ministry of education and Ministry of heath. The nurses play very important role (in different sectors:- government, NGO an INGO) which are as follows:

- Manager

- Facilitator

- Planner

- Advisor

- Change agent
Evaluator etc.

Teacher

Communicator

Organizer

Co-ordinator
Motivator

Supervisor

Problem solver

Policy maker

Researcher

\section{Trends in nursing profession and today:}

Change is natural process. No situation is static for a long time. Trends in nursing is not isolated. The general change in society today are due to: educational change, education is more research oriented - when people become educated they understand value of health service.

\section{Changing in the health care system:}

In modern scientific age we are rapidly adopting high technologies. Medical technology is advancing and being use in the field of health, for promotion of health, prevention of disease and maintenance of health in the diagnostic and therapeutic realms. Yet we Nepalese people are not fully adopting the scientific technology we are using traditional way during treatment. 
According to the P. HC. system we have to accept the good and useful traditions and dis harmful ones. We nurses have country. According to the demand. Nursing education educther of public in every colesin 1972. Bachelor degree in nursing started in $1977 \mathrm{AD}$ in Kath $\mathrm{was}_{\text {bro }}$,

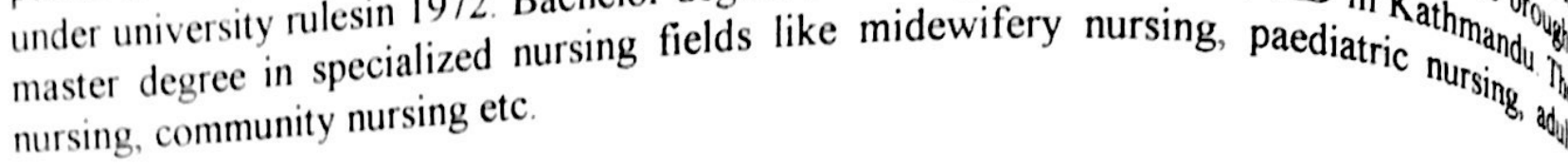

\section{Important of Nursing research:} the relevant nursing interacting factors. In the asses research in the field of nursing has not been done sufficiently. Nurses are providingess, in effective health care service is that nurses should be more knowledgeable dimand effective health care service is that nurses should be more know every field of nursing.
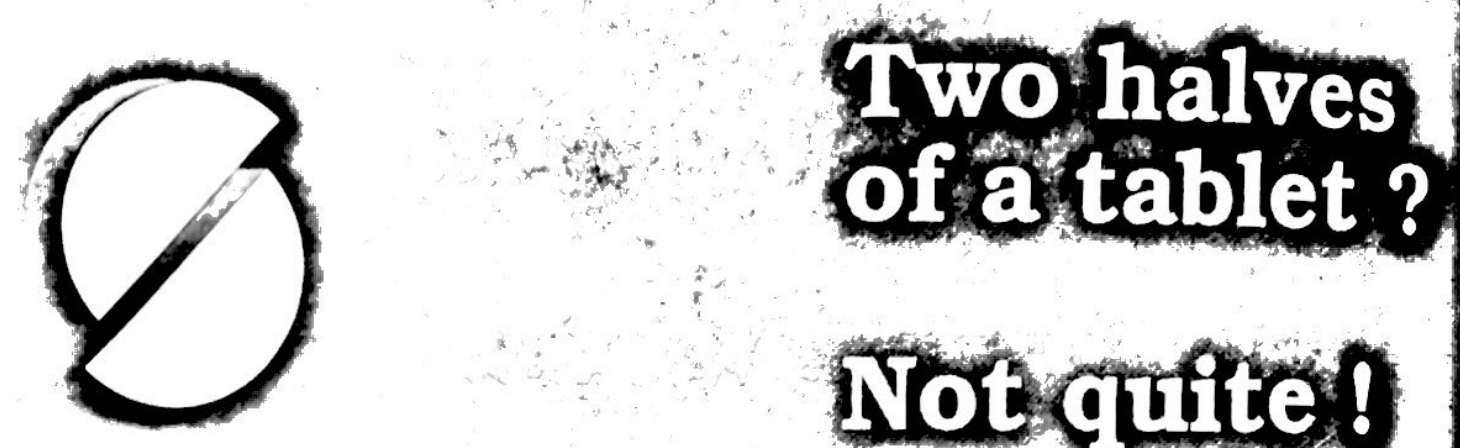

Notquifte?

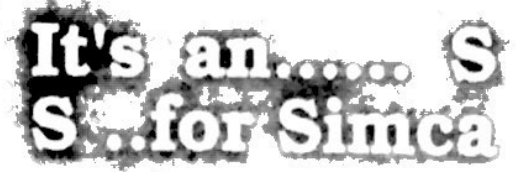

\section{Symbol of excellence in pharmaceuticals}

Slmca Laboratories Pvt. Ltd.

Thimi. Nepal

Tel : 227868 